\title{
A forma de morar: a transformação da casa brasileira à luz das normas reguladoras da estética da paisagem e das edificações
}

Anamaria de Aragão Costa Martins ${ }^{1}$

\section{Resumo}

A estética da paisagem das cidades brasileiras é condicionada por normas urbanísticas e edilícias que expressam ideais estéticos, higiênicos, morais e de costumes. As edificações, em especial, as residências, são o reflexo de tendências de comportamentos e valores sociais definidos no âmbito da vida pública e da vida privada. Este artigo analisa a transformação da tipologia da habitação brasileira, como resultado da alteração dos regulamentos urbanos, ao longo do tempo, que refletem os diferentes valores sociais.

Palavras-chave: Espaço doméstico. Projeto residencial. História urbana. Normas e códigos urbanos.

\section{Introdução}

A paisagem das cidades brasileiras é condicionada por normas urbanísticas que definem afastamentos em relação à rua, alturas de edificações, taxas de ocupação do solo, tipos de atividades, cabendo às normas edilícias definir os pré-requisitos mínimos para o funcionamento dos espaços internos dessas edificações. Tais princípios refletem ideais estéticos, higiênicos, morais e de costumes. Nesse

\footnotetext{
1 Arquiteta e Urbanista pela Universidade de Brasília - 1995. Doutora pelo Departamento de Urbanismo da Universidade Politécnica da Catalunha (Barcelona) - 2004. Urbanista do Governo do Distrito Federal, desde 1996. Integrante da equipe de urbanistas do Estúdio de Joan Busquets (Harvard - UPC) entre 2001 e 2004. Professora do Curso de Arquitetura e Urbanismo da FATECS do UniCEUB desde 2009. E-mail: aragao.anamaria@gmail.com
} 
sentido, as edificações das cidades são o reflexo de tendências de comportamentos e valores definidos socialmente no âmbito da vida pública e da vida privada.

A existência de leis e regulamentos sobre o uso do solo resulta do conceito de direito de propriedade. A análise da evolução desse conceito demonstra que, apenas a partir do século XIX, com os movimentos sociais oriundos da burguesia, fica fortalecida a ideia de função social da propriedade, em oposição ao direito do dono da terra em dispor de sua propriedade de modo pleno e absoluto (MALAGUTTI, 1996). Configurando esse interesse coletivo, subjazem os valores sociais, variáveis ao longo do tempo, e determinados pelas classes dominantes.

O presente trabalho analisa a transformação da tipologia da habitação brasileira à luz da alteração dos princípios que orientam a estruturação dos regulamentos do poder público, sejam normas edilícias ou de posturas. O espaço doméstico, ao explicitar os valores e comportamentos das esferas pública e privada, e, estando sujeito a orientações do poder público, cujas normalizações também refletem os anseios das classes dominantes, constitui exemplos que permitem reconhecer quais são os valores presentes nos diferentes períodos.

\section{A regulações do estado: estratégias de moralização social}

Mesmo nos núcleos do período colonial, habitualmente tratados pelos historiadores como o resultado de um traçado espontâneo, observa-se a influência de normatizações quanto à paisagem urbana, decorrentes do controle sobre os parâmetros edilícios.

A partir das Ordenações Afonsinas (1446), Manuelinas (1521) e Filipinas (1603), as Câmaras Municipais no Brasil colonial, além das tarefas de cobrança, de taxas de serviços e gêneros, de organização de festas populares e de proceder ao julgamento sobre disputas, eram responsáveis pela realização de obras públicas e pelo estabelecimento das posturas municipais (CAMPOS, 1988). Delson (1997) aponta tendências de planejamento do espaço urbano que podem ir ao encontro dos princípios das "posturas municipais": designar ao Estado a responsabilidade por zelar pela 
ordem pública, especialmente no que tange à higiene, ao direito de vizinhança e à estética urbana. Como aponta Costa (1974), a expressão "posturas municipais" surge para diferenciar as colocações administrativas e regulamentares dos municípios das leis e decretos emanados do Governo provincial e central.

Reis Filho (1997), no estudo sobre a urbanização brasileira, demonstra que as casas coloniais eram construídas de modo uniforme, padrão eventualmente fixado nas Cartas Régias ou em posturas municipais, com o objetivo de garantir a estética das vilas coloniais brasileiras. Dentre os parâmetros apontados por Reis (1997), estariam a definição de dimensões e números de aberturas, a altura dos pavimentos e o alinhamento com as edificações vizinhas.

No século XVIII, imbuída de um espírito europeizador e desenvolvimentista para o Brasil, a Administração Pombalina reforçou o papel regulador das Câmaras Municipais no sentido de ordenar a ocupação e o uso do solo nos núcleos de interior do Brasil, especialmente no Norte. Não apenas o traçado urbano, mas a configuração do casario com vistas ao "olhar público" passaram a ser objeto de cuidado do Estado (DELSON, 1997). A estética das edificações e do espaço público deveria corresponder aos ícones de civilidade que a Coroa desejava imprimir à sua colônia mais promissora.

A abertura dos portos brasileiros em 1808 e a Missão Artística Francesa em 1816 introduzem princípios acerca dos padrões construtivos embasados nos ideais burgueses de vida e nas preocupações higienistas. Na arquitetura, grande influência sanitarista advém com arquitetos da missão francesa (CAMPOS, 1988), como Grandjean de Montigny, no Rio de Janeiro e Vaulthier, no Nordeste, que passam a influenciar a alteração dos padrões construtivos das edificações, a partir da crítica sobre as normas das cidades brasileiras.

Com a independência brasileira, a função do Estado altera-se e a administração pública municipal tem suas funções restringidas, em uma tentativa de centralização política. As posturas municipais, no entanto, permanecem entre as funções específicas do município, dadas suas atribuições de cunho administrativo. 
A preocupação higienista e sanitarista do período, decorrente da crítica sobre a cidade industrial europeia, passa a comparecer nas normas municipais. Lewis Munford, descrevendo os cenários das casas das cidades industriais europeias, constata a ausência de infraestrutura de saneamento, especialmente a presença de água, e a vivência promíscua da família. Como características comuns das habitações, encontram-se janelas estreitas, possibilitando pouca presença de luz nos espaços internos, ausência de espaços abertos para as crianças, utilização dos porões como moradia. Consequentemente, muitas doenças surgem nesse período, como o raquitismo, a varíola, a tifo, a deficiência no funcionamento das glândulas endócrinas, inaugurando a preocupação com a transformação dos espaços de vivência privados e públicos.

Os princípios sanitaristas europeus, no ramo da medicina urbana mencionada por Foucault (1979), tinham por objetivo analisar, no espaço urbano, possíveis focos de fatores patógenos, que se amontoariam em espaços da cidade (daí uma das razões para o alargamento das ruas e para a preocupação com o despejo de dejetos sobre elas). Além disso, tais princípios orientaram o planejamento urbano na organização dos equipamentos urbanos (praças, mercados, matadouros) e sua interface com a circulação de animais, com áreas de lavagem de roupas e de despejo de dejetos humanos, que marcam o conteúdo das normas de posturas desse período.

O medo da cidade insalubre reflete-se nas inúmeras teses médicas que influenciam o conteúdo das posturas municipais. Dessa preocupação, são estruturados princípios sobre a higiene pública e sobre as habitações que orientam grandes transformações na estrutura do espaço urbano. Normas sobre drenagem de águas estagnadas, despejo de dejetos em vias públicas, localização de cemitérios e indústrias, mínimos condicionantes de ventilação e iluminação do interior das edificações são ordenados nas posturas municipais, com o objetivo de coibir a proliferação de doenças. Como menciona Campos (1988, p. 42-55), os trabalhos "Climatologia, topografia e insolação domiciliar”, redigido por Francisco de Paula Cândido, presidente da junta central de Higiene Pública do Rio de Janeiro entre 1851 e 1863, influenciou sobremaneira o pensamento sanitarista do País.

Segundo Simões Júnior (2003), os trabalhos do engenheiro Victor Freire Júnior, da Politécnica de São Paulo, no âmbito das discussões sobre o Código de Obras 
de São Paulo editado em 1920 sob o nome de Padrões Municipais, são um marco na definição de parâmetros para os ambientes internos das edificações, baseados em novos critérios de higiene, envolvendo a necessidade de ar e luz nos aposentos. Essa discussão envolveu a questão da dimensão e altura do pé direito dos cômodos e os tipos de janelas a serem empregados nas edificações. Freire Júnior será o responsável, junto a outros engenheiros pela introdução de conceitos de insolação na legislação brasileira (SIMÕES JÚNIOR, 2003).

No século XX, o movimento moderno reforçou a tendência higienista, manifestada, especialmente, na ideia de setorização das atividades, na escala urbana, e nos princípios mínimos de iluminação e ventilação que deveriam estar presentes no espaço interno. A influência de Le Corbusier no Movimento da Arquitetura Moderna Brasileira reforça essas ideias, uma vez que os princípios subjacentes à sua teoria arquitetônica estruturam novos modelos arquitetônicos e urbanísticos, em repúdio à organização da cidade industrial europeia.

A Carta de Atenas, documento consolidador do Congresso Internacional de Arquitetura Moderna - CIAM de 1933, traduz em seu texto tais princípios. No trecho em que se analisa o estado das cidades, destacam-se questões, como as altas densidades, a falta de espaços verdes, a "desordem higiênica", a implantação desfavorecida dos bairros mais densos (em zonas afetadas por gases industriais, em encosta ou áreas passíveis de inundações), e a boa implantação das "habitações ricas" (arejadas, insoladas e voltadas para "perspectivas paisagísticas"). Além disso, a Carta de Atenas estrutura conclusões que influenciam as normas construtivas e urbanísticas, tais como:

$\mathrm{O}$ alinhamento tradicional das habitações à beira da rua só garante insolação a uma parcela das moradias; [...] o zoneamento é a operação feita sobre um plano de cidade com o objetivo de atribuir a cada função e a cada indivíduo seu justo lugar $[\ldots]$

[...] 26- Um número mínimo de horas de insolação deve ser fixado para cada moradia [...] Todo projeto de casa no qual um único alojamento seja orientado para o norte, ou privado de sol, devido às sombras projetadas, será rigorosamente condenado [...] Na falta disso será negada a autorização para construir [...] (INSTITUTO DO PATRIMONIO HISTORICO E ARTISTICO NACIONAL, 1995). 
De forma mais contundente, a Carta de Atenas propõe a remodelação de bairros antigos, alegando que "bairros inteiros deveriam ser condenados em nome da saúde pública”.

Até o presente, grande parte de normas reguladoras, mesmo as recentemente revisadas, mantém em seu conteúdo a preocupação com águas servidas, despejo de lixo, animais e pragas urbanas, do que se observa que a preocupação sanitarista ainda perdura.

Observando-se a alteração dos valores sobre posturas municipais frente aos direitos individuais, torna-se possível identificar dois momentos tipológicos da estrutura da casa brasileira: a conformação colonial, produto de uma concepção de vida privada e pública interdependentes e em parte resultado de tentativas de ordenamento da paisagem urbana orientadas pela Coroa Portuguesa, e a tipologia burguesa, resultado da banalização dos valores burgueses sobre a vida privada e pública e decorrente de preocupações sanitaristas.

A casa modernista e a casa contemporaneamente edificada são resultados desta última tipologia. Mesmo nas casas de população de baixa renda, cuja concepção sobre vida privada e vida pública mais se aproximam da interdependência da tipologia colonial, fica explícita a influência da casa burguesa. Não se pode deixar de mencionar que o tema do projeto de habitações populares se estrutura na tentativa de erradicação de cortiços (BRANDÃO, 1982), com base em parâmetros burgueses sobre a forma de morar. Assim, a tipologia da casa popular decorre da aplicação das mesmas normas construtivas adotadas para edificações de alta renda, reduzindo aos mínimos os parâmetros tipológicos da casa burguesa.

\section{A apropriação do espaço doméstico no contexto familiar, individual e público}

A organização do espaço doméstico revela os papéis sociais que extrapolam as regras sociais do viver em família, refletindo representações sociais decorrentes 
da assimilação de estratégias educacionais, pedagógicas, econômicas, profissionais e culturais. Na trajetória do estudo da casa tradicional brasileira, os pesquisadores que analisaram o tema pautaram-se na estrutura da casa como reflexo do sistema escravocrata da colonização e associaram a transformação do morar tradicional com a abolição da escravatura e com a absorção de referências culturais não ibéricas resultantes do processo de imigração.

O estudo do espaço doméstico permite a percepção das relações de poder, das estratégias de institucionalização das relações sociais no âmbito privado e da influência das normas construtivas. Da transformação dos espaços domésticos, é possível perceber quais funções sociais são transferidas da esfera privada para a pública e vice-versa, e quais mecanismos sociais, sejam leis e normas, ou apenas convenções apoiam tal transformação.

Homem (1996) decompõe a casa burguesa em três zonas: zona de serviço, zona de repouso e zona de estar. Ao se tratar da casa popular, tais divisões são menos percebidas, além de existir uma zona semipública que, neste trabalho, denominar-se-á, zona de trabalho.

A zona de serviço é composta pela cozinha, pelo quintal e pelo sanitário externo ou anexo a casa e pela copa da casa burguesa que se vulgariza assumindo a função da sala de jantar nas casas populares. A zona de serviço remete ao espaço do escravo e da mulher (sinhá) na casa colonial, do serviçal, na casa burguesa do ecletismo e ao espaço de convívio da gente comum, na casa popular.

A zona de repouso engloba quartos e alcovas. A substituição das alcovas pelos quartos individualizados e ventilados provoca a transformação dos espaços externos e internos da casa. São consequência da forma como os padrões burgueses são assumidos, por meio da visão higienista dos códigos de posturas do início do século (NOVAIS, 1997). Em São Paulo, Homem (1996), aponta os códigos de 1873, de 1886 e de 1894 como indutores da transformação da divisão dos espaços internos e da conformação externa da casa, dados os pressupostos higienistas que apresentam. No Rio de Janeiro, as ideias higienistas prevaleceram nas reformas urbanas dos anos 20 , 
no combate aos cortiços no governo Pereira Passos, e no novo código de posturas e edificações, que primavam pela extinção de um modo de vida promíscuo associado à pobreza e à proliferação de doenças.

Da mesma forma, a definição de espaços de repouso individualizados, e não mais familiares, demonstra novas fronteiras entre as esferas da vida cotidiana: a vida pública (ligada ao trabalho e ao lazer), a vida privada familiar e a vida privada individual, construídas a partir do direito a não integração com os demais membros da família, do direito ao segredo, do culto ao corpo, do êxito do esporte, do medo de doenças (PROST; VICENT, 1992).

À zona de estar, integram-se as salas de visitas e outros cômodos semipúblicos. Transforma-se de espaço da informalidade familiar a espaço de veiculação da imagem pública da família na casa burguesa eclética (HOMEM, 1996), hoje imprescindível nos projetos residenciais.

Já a zona de trabalho, na casa popular, esteve vinculada à estrutura do trabalho doméstico presente nos núcleos urbanos coloniais. Nestes, a casa desempenhava simultaneamente o espaço da família e do trabalho. Os filhos partilhavam momentos da vida do casal, assim como o trabalho era, em grande parte, familiar. Cada membro da família tinha uma tarefa, mas a renda da produção era da família, socializada, portanto, por seus membros (PROST; VICENT, 1992). O armazém conjugado a casa ou no andar térreo caracteriza os sobrados coloniais das cidades brasileiras, assim como o comércio na frente da casa nos bairros de baixa renda.

\section{A cozinha, a copa e a sala de visitas: os limites da informalidade}

Enquanto na casa colonial rural a cozinha estava localizada externamente a casa, no sobrado urbano colonial, ocupava área de destaque no andar térreo. Carlos Lemos (1978), ao analisar as zonas de serviços das casas paulistas populares e burguesas, atribui a exteriorização desse espaço às altas temperaturas emanadas dos fornos. Se na casa portuguesa, o clima favorecia a instalação de fornos no interior da 
casa, com a fumaça escapando pelas chaminés, no caso brasileiro, a solução do fogão no interior era motivo de fumaça e sujeira.

Carlos Lemos (1978) aponta os relatos de viajantes que apresentavam a cozinha da casa colonial, seja nas propriedades rurais, seja em área urbana como o centro das atividades, ainda que fossem dependentes dos equipamentos que se localizavam no quintal onde era feito o trabalho 'sujo'. Reflete, em seguida, sobre a separação das atividades da cozinha em dois espaços, vinculados justamente à necessidade de manter distantes as atividades 'extrovertidas', como lavar roupa no ribeirão, torrar farinha e produzir sabão, no quintal, das atividades frequentadas pelo patrão e pela sinhá, desenvolvidas em espaços que poderiam ser eventualmente transformada em sala de costura ou de estar.

O espaço classificado atualmente como copa origina-se no processo de separação entre as duas cozinhas. A copa, espaço de transição entre a varanda e a zona de serviço externa ou a área da cozinha limpa, torna-se espaço de convívio familiar.

$\mathrm{Na}$ casa popular, a ideia de espaço familiar é expandida às relações de vizinhança. Assim, a copa/sala de visitas é o espaço natural para se receber a visita íntima.

Se por um lado o espaço do convívio informal é a copa, a ideia de formalidade se expressa na inclusão da sala de visitas como espaço semipúblico destinado aos convidados mais formais.

Segundo Maria Cecília N. Homem (1996), a sala de visitas insere-se na zona de representação da casa burguesa, que exige decoro em dupla acepção: o decoro moral e o decoro arquitetônico, correspondendo aos valores formais, emocionais e espirituais da arquitetura (EGBER, 1980), portanto, de seus donos. Assim, compete organizar a sala de visitas com mobiliário apropriado, sejam peças trazidas de viagens ao exterior que ficam à mostra em vitrines, sejam objetos deixados, cuidadosamente, ao acaso sobre os móveis. 
A copa desapareceu nos projetos residenciais dos apartamentos contemporâneos devido à redução das dimensões dos cômodos para a maior rentabilidade do empreendimento. A sala de visitas absorve a atividade de convívio familiar, seja informal ou formal. Apenas nos projetos de casas, tais distinções permanecem presentes na demanda dos proprietários.

\section{0 quintal e os jardins}

O quintal pode ser analisado na perspectiva das transformações dos significados públicos e privados dos espaços domésticos. Se na casa colonial o quintal representava um espaço de definição da distância social, separando os escravos dos senhores, na casa burguesa a função permanece, mas voltada para a diferenciação dos espaços do trabalhador assalariado e dos patrões, na acepção de Lemos (1978).

Já na interpretação de Maria Cecília N. Homem (1996), é o quintal que revela a face privada da vida da mulher da sociedade colonial: a do trabalho doméstico, impróprio à cultura da colônia em que não trabalhar constituía o elemento diferenciador entre os homens livres e escravos. Por trás dos muros do quintal, a sinhá participava da preparação dos produtos a partir dos quais se obtinha parte da renda familiar e que era vendido, à vista de todos, pelos escravos de propriedade da família.

A casa popular interiorana manteve a tradição do uso do quintal como espaço coletivo. Na casa popular semirrural goiana, o quintal de 'terra batida' estende as atividades de lavagem dos telheiros da casa colonial paulista, mencionadas por Lemos (1978). É o varal das roupas que se secam ao sol, o local de produzir sabão artesanal.

Desde meados do século XIX a primeiras décadas do século XX, como aponta Nestor Goulart dos Reis Filho (1997, p.72-74) os quintais “só permaneceram em lotes grandes, que abarcavam também pátios de manobra e renques de árvores não frutíferas, [...] ou quando se tratava de 'mau gosto' do proprietário ou descaso arquitetônico". Os fundos do quintal seriam, sob esta ótica, o espaço apropriado aos resquícios culturais do período colonial, inconcebível na civilidade da casa burguesa. 
Ainda de acordo com Reis Filho (1997), os quintais se reduzem na perspectiva de transformação da ocupação do lotes, em virtude dos códigos higienistas que predominam na década de 1920. Inicialmente os jardins laterais e, posteriormente, os jardins frontais, surgem como resultado dos afastamentos obrigatórios propostos pelos códigos de posturas de então. $\mathrm{O}$ afastamento configura acessos e institui uma separação formal entre a casa e a rua. Ao permitir entradas laterais a casa, extingue-se a relação direta entre a casa e a rua proporcionada pelas portas voltadas diretamente ao espaço público. De fato, os afastamentos laterais e frontais instituem espaços de transição, eliminando o papel de outras estruturas internas a casa, como os porões altos que protegem a intimidade familiar do olhar anônimo das ruas.

Justificado pela necessidade de ventilação dos cômodos, o jardim lateral também acarreta grandes modificações no ordenamento dos espaços internos da casa. Especialmente nos lotes mais estreitos, na casa operária, a tipologia do espaço doméstico sofre adaptações recuperando traços da distribuição da casa colonial em que a transição entre cômodos é feita por meio de outros cômodos, dada à necessidade de todos os espaços estarem voltados para os referidos jardins laterais (diante das exigências dos códigos de edificações e posturas). Além das implicações sobre os limites público e privado da casa, os jardins laterais implicam alterações no significado de privacidade dos espaços internos.

Os jardins frontais, como bem expressa Reis Filho (1997), traziam as preocupações com o fachadismo, com rebuscamentos decorativos e implicavam a construção de bancos, quiosques, 'grutas de cimento', anões de louça colorida, aparato destinado a explicitar aos olhares dos passantes a imagem pública da família. Na cultura norte-americana, a preocupação com o aspecto dos gramados dos jardins frontais da casa expressa o significado desse espaço de transição ou de anúncio da face pública que se deseja exteriorizar. Até mesmo o jardim do vizinho mal cuidado pode por em risco a imagem de toda a rua. Na cultura brasileira, esse tipo de preocupação com a face pública é revelada pela ostentação, por exemplo, nos tipos de grades utilizadas para circundar suas áreas ajardinadas.

Com o movimento moderno, o conceito de afastamentos laterais foi ampliado pela concepção das áreas livres coletivas, externas aos lotes e teoricamente 
destinadas ao uso público. Os lotes têm suas dimensões reduzidas e seu potencial construtivo aumentado. Os espaços, ora destinados aos quintais ou aos jardins frontais e laterais são transferidos para as áreas verdes públicas. Tal inversão altera o sentido da conformação da rua, que passa a não mais ser definida pelas massas construídas à sua volta, mas pelos limites físicos das vias de circulação de veículos.

Nos espaços domésticos de baixa renda, porém, alterações nas normas de uso e ocupação de solo nos lotes, construções ditas "provisórias" nos afastamentos frontais, eliminam a separação entre o público e o privado para retomar a tipologia de ocupação do solo da casa colonial, contígua às calçadas.

\section{A alcova, os quartos e o porão}

Enquanto no sobrado paulista as alcovas desempenhavam muitas vezes a função de espaço de transição (entre o estar formal e o estar informal da família), na casa burguesa as alcovas são transformadas em salas de costuras, como resultado das exigências higienistas da legislação. Gilberto Freyre (1997) relembra o trabalho de Pires de Almeida sobre a higiene das habitações ${ }^{2}$, em que menciona como elementos característicos da habitação tradicional luso-brasileira a alcova, o corredor e a área de serviço. Freyre (1997, p. 233) complementa ainda que as alcovas sem janelas representavam modos de controle do comportamento das sinhás-moças: eram "prisioneiras mais bem guardadas do que os presos na Cadeia do Brejo, construída ou planejada por Vaulthier com tanta atenção pelos detalhes de segurança”

A alcova ainda foi utilizada como habitação de empregados, na adequação dos espaços da loja/armazém no andar térreo dos sobrados, com a retração do trabalho domiciliar. As premissas de iluminação e ventilação, as medidas de precaução contra doenças primavam pela extinção de um modo de vida promíscuo associado a não-diferenciação dos espaços (NOVAIS, 1997). As alcovas, assim, tiveram de ser adaptadas, transformando-se em quartos.

\footnotetext{
${ }^{2}$ Inspetoria Geral de Higiene, parecer do Dr. Pires de Almeida, 1884.
} 
Na década de 1880, a prefeitura de São Paulo passa a aprovar projetos residenciais e institui mínimos construtivos e regras para o uso dos cômodos: abolem-se as alcovas e é estabelecida uma dimensão mínima para as habitações, como os 14 metros cúbicos livres para cada dormitório (SÃO PAULO (Estado), 1984). Disciplina-se também a localização dos cômodos (as cozinhas ficariam longe da zona de repouso), definindo a planta da casa contemporânea.

A ideia de dimensões mínimas para os quartos, a exigência de ventilação e iluminação para os cômodos de permanência prolongada, são os resultados das normas que passam a valer em princípios do século XX. Talvez o único resquício das alcovas sejam as dimensões diminutas dos quartos de empregada, onde a ideia de mínimos de ventilação e iluminação é seguida a risca pelos arquitetos em nome de efeitos de fachada, muitas vezes duvidosos.

\section{0 armazém e a sala de estar}

A tipologia da casa-armazém está presente no sobrado e na casa térrea colonial. A localização do estabelecimento comercial no ponto mais próximo ao espaço público (seja o andar térreo, seja a parte frontal do lote) configurou uma estrutura arquitetônica que resguardou o espaço privado do público.

A retração do trabalho domiciliar, entretanto, transformou essa situação e, paulatinamente, permaneceu apenas a zona de estar na casa burguesa. A retração do trabalho domiciliar é resultado da reivindicação ao direito à vida privada e da instituição de regras trabalhistas, tais como horário de trabalho, direito a férias e equiparação salarial, outrora tratadas em acordos entre patrão e empregado, baseados em relações de poder unilateral (do empregador).

Nas grandes cidades, a instauração de normas de uso do solo, seguiu a perspectiva modernista da separação das funções, inibindo a prática do trabalho domiciliar. Entretanto, nas áreas de baixa renda, permaneceu como resultado da economia informal decorrente das dificuldades econômicas enfrentadas por grande parte da população brasileira. 
Sendo assim, na casa popular, permanece a existência de uma zona de trabalho - o armazém, a oficina, o cabeleireiro - e a zona de estar, representando o espaço da vida privada.

\section{Considerações finais}

Como se procurou demonstrar anteriormente, os espaços domésticos assumem diferentes significados não apenas como consequência dos valores individuais ou familiares, mas em função de códigos urbanos e arquitetônicos vinculados à idéia de civilidade (urbanidade e higiene), como contraposto ao atraso (ruralidade) ou à diferença de classes sociais (burguesia e proletariado).

Se, por um lado, a casa brasileira transformou-se radicalmente até meados do século XX, nos últimos 50 anos continua-se a reproduzir as tipologias modernistas sobre a "correta" forma de morar. Forma, esta, derivada de códigos formais ou informais, baseados em princípios que repudiam possíveis promiscuidades geradas pela não separação dos espaços destinados a diferentes atividades ou atores e que estabelecem padrões reproduzindo parâmetros higienistas de normas anteriores.

Ao se analisar prospectos de oferta de novas unidades imobiliárias, sejam prédios de apartamentos ou s pré-fabricadas, constata-se que não há variação na tipologia ofertada. Podem variar quantidades e dimensões de cômodos, mas a estrutura burguesa e sanitarista permanece. Espaços com áreas delimitadas (cozinha, quartos, banheiros e salas de estar), restrições quanto à utilização da casa para outras atividades que não a de moradia, complementam a ideia de que a população vive, sem se dar conta, em um padrão arquitetônico, reflexo de valores morais, culturais e legais.

Por outro lado, em áreas ocupadas irregularmente, onde as habitações não estão sujeitas a regras formais e onde, obviamente, não existem recursos 
financeiros para se sucumbir ao modelo burguês, transparece que a tipologia usual não é a mais utilizada. No entanto, sob o argumento da pobreza e da falta de infraestrutura, a sociedade conforma-se com o fato de que tais construções sejam menos "civilizadas".

Ao intervir sobre a temática da casa popular, pouco se reflete sobre a forma de morar das camadas populares, inclusive as formas de organização dos espaços internos. Como reflexo da desconsideração de uma maneira particular de apropriação do espaço doméstico, os programas habitacionais reproduzem a estrutura da casa burguesa reduzida aos mínimos permitidos.

A extrapolação no nível urbano da ideia de mínimos, que reduzem a casa operária à miniatura da casa burguesa, pode ser observada na exceção que se faz à dimensão de lotes populares na lei federal de uso e ocupação do solo (Lei 6.766/79). Essa lei estabelece dimensões mínimas $(125 \mathrm{~m} 2)$ para os lotes residenciais, à exceção de parcelamentos de interesse social que podem apresentar dimensões ainda menores, a juízo das leis estaduais.

No entanto, as normas urbanísticas para grande parte desses lotes continuam mantendo a ideia de afastamentos obrigatórios (no interior do lote) ou guardam, no traçado urbano, a lógica modernista de áreas verdes públicas, separando o lote da rua. Naturalmente, dado aos valores diminutos dos lotes, os afastamentos obrigatórios são desrespeitados com construções precárias adicionadas com o tempo e as áreas verdes são invadidas.

Cabe, portanto, refletir criticamente sobre os valores burgueses vinculados à vida pública e privada presentes nos projetos residenciais e nos códigos urbanos e edilícios. Distinguir novas formas de morar, novas estruturas familiares, novas tendências de organização da vida privada, e novas dinâmicas da vida laboral poderá contribuir na produção de diferentes arquiteturas domésticas, libertas, finalmente, de conceitos pré-determinados sobre uma forma "civilizada" e "moderna" de morar. 


\section{The way of living: the transformation of brazilian housing typology according to urban and building regulation}

\section{Abstract}

The image of urban landscape is determined by urban rules and building standards that express aesthetic and hygienic purposes, as well as moral conventions. Architecture, and the house in special, is the reflex of behavior tendencies and social values defined inside public and private life. The article analyses the transformation of Brazilian housing typology according to social behavior changes and different urban regulation during time.

Keywords: Domestic space. Housing. Urban history. Urban regulation.

\section{Referências}

BRANDÃO, Arnaldo Barbosa. Morar e viver: um estudo sobre a habitação das famílias pobres. 1982. 62 f. Dissertação (Mestrado)-Faculdade de Arquitetura e Urbanismo, Universidade de Brasília, Brasília, 1982.

BRASIL. Lei no 6.766, de 19 de dezembro de 1979. Dispõe sobre o parcelamento do solo urbano e dá outras providências. Brasília, 1979. Disponível em: $<$ http://www. planalto.gov.br/ccivil_03/Leis/L6766.htm>. Acesso em: 06 abr. 2010.

CAMPOS, André Luiz Vieira de. Posturas municipais na Província Fluminense: os casos de Niterói e Campos. Revista de Administração Municipal, Rio de Janeiro, v. 35, n. 188, p. 42-55, jul./set. 1988.

COSTA, Antonio Tito. "Posturas municipais" e o novo código de processo civil. Revista da Procuradoria-Geral do Estado [do Rio Grande do Sul], Porto Alegre, v. 4, n. 8, p. 71-74, 1974.

DELSON, Roberta Marx. Novas vilas para o Brasil colônia: planejamento espacial e social no século XVIII. Brasília: ALVA-CIORD, 1997.

DISTRITO FEDERAL. Lei no 2.105, de 08 de outubro de 1998. Dispõe sobre o Código de Edificações do Distrito Federal. Brasília, 1998. Disponível em: <http:// 
sileg.sga.df.gov.br/legislacao/Distrital/LeisOrdi/LeiOrd1998/lei_ord_2105_98. html>. Acesso em: 12 mar. 2010.

EGBER, Donald Drew. The beaux-arts tradition in french architecture. New Jersey: Princeton University, 1980.

FOUCAULT, Michel. Microfísica do poder. Rio de Janeiro: Graal, 1979.

FREIRE, Victor da Silva. A cidade salubre. Revista Polytechnica, São Paulo, v.8, n.48, p. 320-354, out./nov. 1914.

FREYRE, Gilberto. Casa de residência no Brasil. Revista do Patrimônio Histórico e Artístico Nacional, Rio de Janeiro, n. 26, p. 224-238, 1997. Edição Comemorativa dos 60 anos.

HOMEM, Maria Cecília Naclério. O palacete paulistano e outras formas de morar da elite cafeeira: 1867-1918. São Paulo: M. Fontes, 1996.

INSTITUTO DO PATRIMÔNIO HISTÓRICO E ARTÍSTICO NACIONAL. Cartas patrimoniais: caderno de documentos n 3. Brasília: MINC, 1995.

LEMOS, Carlos. Cozinhas, etc. 2. ed. São Paulo: Perspectiva, 1978.

MALAGUTTI, Cecília Juno. Loteamentos clandestinos no DF: legalização ou exclusão? 1996. 232 f. Dissertação (Mestrado)-Faculdade de Arquitetura e Urbanismo, Universidade de Brasília, Brasília, 1996.

NOVAIS, Fernando (Coord.); SOUZA, Laura de Mello e (Org.). História da vida privada no Brasil: cotidiano e vida privada na América Portuguesa. São Paulo: Companhia das Letras, 1997. v. 1.

PROST, Antoine; VICENT, Gérard (Org.). História da vida privada: da Primeira Guerra aos nossos dias. São Paulo: Companhia das Letras, 1992. v. 5.

REIS FILHO, Nestor Goulart dos. Quadro da arquitetura no Brasil. 8. ed. São Paulo: Perspectiva, 1997.

SÃO PAULO (Estado). Decreto no 233, de 2 de março de 1894. Estabelece o Código Sanitário. Em Collecção das leis e decretos do estado de São Paulo de 1894. Diário Oficial [da] República Federativa do Brasil, Rio de Janeiro, 1895, p. 9-43. 
SIMÕES JÚNIOR, José Geraldo. A pesquisa e o debate urbanístico em São Paulo (1900-1920): as proposições em torno do tema da casa e cidade salubres. Trabalho apresentado em sessão livre na X ENANPUR, junto ao grupo de trabalho "O urbanismo sanitarista no Brasil Republicano" da Escola de Engenharia de São Carlos, USP, em 2003. Disponível em: <www.usjt.br/arq.urb/numero_01/ artigo_03_a_180908.pdf >. Acesso em: 16 jun. 2010. 